\title{
O imaginário das águas e o aprendizado erótico do corpo*
}

\section{The imaginary of the waters and the body's erotic learning}

\author{
Cláudia Maria Ribeiro*
}

\begin{abstract}
RESUMO
No decorrer da história da humanidade as águas imaginárias transbordaram de significações e simbologias no universo cultural do ser humano e brotam como símbolo de contradições. Para além das oposições, problematizar o aprendizado erótico do corpo traz perguntas sobre o processo de civilizador no ocidente. Isto é, de que forma a água perpassou as transformações da relação dos indivíduos com o seu corpo? A relação entre água e Eros é percebida como elemento importante do aprendizado erótico do corpo, tendo em vista o conjunto de regras sobre a utilização desta nos banhos. Sendo assim, o contato com esse elemento é uma das possibilidades de se desfrutar a intensidade dos sentidos? A proximidade com a água possibilita a transgressão? $\mathrm{O}$ artigo navega pelas discussões do imaginário das águas, assim como também pela água como suporte da imaginação e dos (desprazeres dos banhos na história.

Palavras-chave: imaginário; águas; corpos; erotismo.
\end{abstract}

\footnotetext{
ABSTRACT

Throughout human history, imaginary waters have carried out an overflow of meanings and symbolisms in the cultural universe of human beings, springing as symbols of contradictions. Beyond all oppositions, investi-

* Este texto foi escrito a partir de pesquisas apresentadas na tese de Doutorado defendida em 2001 na Faculdade de Educação da UNICAMP intitulada: "O imaginário das águas, Eros e a

** Professora Adjunta do Departamento de Educação da Universidade Federal de Lavras. Coordenadora do GT 23 - Gênero, Sexualidade e Educação da ANPEd - Associação Nacional de Pós Graduação e Pesquisa em Educação.
} Criança". 
gating the erotic learning of the body brings forward questions about the Occident's civilizing process, such as: in which ways has water pervaded the transformations concerning the individual's relationships with his her bodies? The relation between water and Eros is perceived as an important element for the erotic learning of the body, observed as a set of rules concerning the use of water in bath. Therefore, is contact with water one of the possibilities to enjoying intensity of the senses? Is proximity with water a possibility of transgression? The article navigates through discussions about the imaginary of the waters as well as through water as a support for the imagination and for bath's (un)pleasures in history.

Keywords: imaginary; waters; bodies; eroticism.

\section{Os quatro elementos: hormônios da imaginação}

Os quatro elementos permanecem princípios da criação artística. Bachelard $^{1}$ estuda esse imaginário e passa a valorizá-lo como uma forma própria de apreensão e criação da realidade, imaginando incessantemente e enriquecendose com novas imagens. Os quatro elementos são os hormônios da imaginação. A primeira obra dedicada à imaginação dos elementos foi publicada em 1938 , intitulada A Psicanálise do Fogo (1999). Este livro é uma ilustração das teses gerais defendidas na obra A Formação do Espírito Científico de 1937 (1996).

Inicia-se, assim, a longa série que comporá sobre o imaginário artístico e sobre o sonho acordado - o devaneio. O autor propõe que:

1 Gaston Bachelard (1884 - 1962) trilhou dois sendeiros paralelos em sua obra: ciência e poesia. Buscou fazer não apenas a "psicanálise do conhecimento objetivo" como também a "psicanálise dos elementos". (terra, ar, água e fogo). Teceu considerações tanto em relação à filosofia científica quanto à pedagogia científica. "A filosofia científica deve ser essencialmente uma pedagogia científica". Sua preocupação com os fundamentos e os requisitos para o desenvolvimento de um "novo espírito científico" levaram-no a combater as formas tradicionais de ensino e a propor para a ciência nova uma pedagogia nova [...] Bachelard formulou seu lema de inconformismo intelectual através do que denominou de "filosofia do não". Para ele, a história das ideias não se faz por evolução ou continuísmo, mas através de rupturas, revoluções, "cortes epistemológicos". Num de seus livros escreveu: "A verdade é filha da discussão, não da simpatia". Aplicando ele próprio esse preceito, revestiu toda sua obra de caráter polêmico, fazendo reiteradas críticas à nociva influência da metafísica tradicional (particularmente a cartesiana) sobre o desenvolvimento da epistemologia científica. Em 1937 Bachelard publica uma de suas obras mais importantes, La Formación de l'Esprit Scientifique (A Formação do Espírito Científico), na qual analisa os mais diversos “obstáculos espistemológicos" que devem ser superados para que se estabeleça e se desenvolva uma mentalidade verdadeiramente científica" (BACHELARD, 1978, p. 6-7). 
se considere a imaginação como um poder maior da natureza humana [...] a imaginação, em suas ações vivas, nos desliga ao mesmo tempo do passado e da realidade. Aponta para o futuro. À função do real, instruída pelo passado, tal como é destacada pela psicologia clássica, é preciso juntar uma função do irreal, também positiva, como tentamos estabelecer em obras anteriores. Uma enfermidade por parte da função do irreal entrava o psiquismo produtor. Como prever sem imaginar? (BACHELARD, 1978, p. 195).

A imaginação, portanto, é dinamismo organizador, potência dinâmica que "deforma" as cópias pragmáticas fornecidas pela percepção. As estruturas do imaginário ${ }^{2}$, segundo o autor, são portanto conteúdos dinâmicos como meio fundamental para a compreensão das bases míticas do pensamento humano. Visto das mil janelas do imaginário, o mundo é mutável.

Dessa forma a concepção bachelardiana de imaginação distingue a imaginação formal ${ }^{3}$ e a imaginação material ${ }^{4}$. Bachelard $(1985,1996)$ não perde de vista o fato de que a imaginação torna-se fundamental na criação científica considerando a razão uma atividade psicológica que procura revirar os problemas, variá-los, ligar uns aos outros, fazê-los proliferar.

O novo espírito científico não é fruto de mera contemplação. Ao romper com a tradição intelectualista, cartesiana, o autor não apenas distingue imaginação reprodutora e imaginação criadora; imaginação formal e imaginação material, mas considera que a primeira corresponde ao império da visão, que chama de vício da ocularidade; o novo espírito científico busca o pormenor, evidenciando a intervenção do sujeito na configuração do objeto do conhecimento. Bachelard

2 Imaginário é o "conjunto das imagens e relações de imagens que constitui o capital pensado do homo sapiens; aparece-nos como um grande denominador fundamental onde se vêm encontrar todas as criações do pensamento humano" (DURAN, 1997, p. 18).

3 Para Bachelard: “A imaginação formal, que nutre a formalização, resulta de uma operação desmaterializadora, que intencionalmente "sutiliza" a matéria ao torná-la apenas objeto de visão, ao vê-la apenas enquanto figuração, formas e feixes de relações entre formas e grandezas, como uma fantasmática incorpórea, clarificada mas intangível. E é, na verdade, resultado da postura do homem como mero espectador do mundo, do mundo-teatro, do mundo-espetáculo, do mundo-panorama, exposto à contemplação ociosa e passiva" (BACHELARD, 1985, p. 25).

4 “A imaginação material recupera o mundo como provocação concreta e como resistência, a solicitar a intervenção ativa e modificadora do homem: do homem-demiurgo, artesão, manipulador, criador, fenomenotécnico, obreiro - tanto na ciência quanto na arte. Mais: foi na linhagem do filósofo-voyeur que se desenvolveu toda a tradição intelectualista que concebe a imagem como simples simulacro sem vida e essencialidade próprias - apenas o duplo ou fantasma de um objeto já percebido - e cujo significado deve sempre ser traduzido em conceito" (BACHELARD, 1985, p. 25, 26). 
não foi apenas o filósofo do novo espírito científico, mas soube extrair novos significados das obras de arte. No ensaio que escreveu sobre Monet intitulado As Ninfeias ou as Surpresas de uma Alvorada de Verão escreveu: "Não se sonha junto à água sem formular uma dialética do reflexo e da profundidade" (1985). Monet pintou "a pintura" das águas, reproduzindo incessantemente os quadros líquidos da natureza. Escrevendo a um amigo disse: "Essas paisagens de água e de reflexos tornaram-se uma obsessão". Pessanha (1988, p. 161) analisa esse infindável caminho da reflexão:

O duplo que a água constrói é duplicado na tela do artista, criando enigmas de espelhamento, ecos visuais sem fim. Sobretudo quando a paisagem se reflete numa água tranqüila sob a luz mortiça do amanhecer, o olhar capta e a mão logo reproduz imagens fantásticas que pedem decifração, que testam o intérprete.

A água para Monet é um meio para a abstração. O espelho d'água confunde as regras do jogo da pintura paisagista. Monet continuará a aplicar este princípio sempre que pinta a água, as falésias e particularmente seus famosos nenúfares.

\section{O imaginário das águas}

As águas imaginárias são tema de Bachelard (1998), em A Água e os Sonhos, ensaio de estética literária, em que a maioria dos exemplos são tirados da poesia e da mitologia, objetivando determinar a substância das imagens poéticas. Para tanto o autor evoca imagens superficiais do elemento água dedicando-se às águas claras, às águas brilhantes que fornecem imagens fugidias e fáceis ${ }^{5}$.

5 BACHELARD, (1998, p. 6-7): "Estudaremos as imagens substanciais da água, onde faremos a psicologia da "imaginação material" da água - elemento mais feminino e mais uniforme que o fogo, elemento mais constante que simboliza com as forças humanas mais escondidas, mais simples, mais simplificantes [...] Os documentos poéticos são bem menos numerosos e pobres. Os poetas e sonhadores são por vezes mais divertidos que seduzidos pelos jogos superficiais das águas. A água é, então, um ornamento de suas paisagens; não é verdadeiramente "substância" de seus devaneios [...] se pudermos convencer nosso leitor de que existe, sob as imagens superficiais da água, uma série de imagens cada vez mais profundas, cada vez mais tenazes, ele não tardará a 
Evoca também características profundas da água imaginária - as águas dormentes, as águas mortas, as águas pesadas no devaneio de Edgar Alan Poe:

Toda água primitivamente clara é para Edgar Poe uma água que deve escurecer, uma água que vai absorver o negro sentimento [....] Lendo Poe, compreendemos mais intimamente a estranha vida das águas mortas, e a linguagem ensina a mais terrível das sintaxes, a sintaxe das coisas que morrem, a vida que morre (BACHELARD, 1998, p. 49).

Este autor estuda também a composição da água com outros elementos da imaginação material, principalmente a terra e o fogo ${ }^{6}$. Discorre sobre as imagens impregnadas de mitologia que animam as obras poéticas na maternidade das águas, na sua pureza e também nas águas masculinas, violentas. As artes banham-se nos símbolos.

Eliade (1996) considera que as águas simbolizam a soma universal das virtualidades; elas são fons e origo, e reservatório de todas as possibilidades de existência; elas precedem toda forma e sustentam toda criação. A água é a origem da vida e o elemento de regeneração corporal e espiritual, o símbolo da fertilidade, da pureza, da sabedoria e da virtude.

Hesíodo (apud CHEVALIER; GHEERBRANT, 1998), distinguiu, na Teogonia, água estéril e água fecundante, intimamente ligadas à intervenção do amor. A água feminina, a água doce, a água lacustre, a água estagnada diferenciadas das águas do oceano, espumante, fecundante, masculina.

A valorização feminina, sensual e maternal da água foi cantada pelos

sentir, em suas próprias contemplações, uma simpatia por esse aprofundamento [...] Reconhecerá na água, na substância da água, um tipo de intimidade [...] Deverá reconhecer que a imaginação material da água é um tipo particular de imaginação. Fortalecido com esse conhecimento de uma profundidade num elemento material, o leitor compreenderá enfim que a água é também um tipo de destino, não mais apenas o vão destino das imagens fugazes, o vão destino essencial que metamorfoseia incessantemente a substância do ser. Por isso o leitor compreenderá com mais simpatia, mais dolorosamente, uma das características do heraclitismo. Verá que o mobilismo heraclitiano é uma filosofia concreta, uma filosofia total. Não nos banhamos duas vezes no mesmo rio, porque, já em sua profundidade, o ser humano tem o destino da água que corre. A água é realmente o elemento transitório".

6 (BACHELARD, 1985, p. 14): “Certas formas poéticas se nutrem de uma dupla matéria; que um duplo materialismo trabalha freqüentemente a imaginação material. Em certos devaneios, parece que todo elemento busca um casamento ou um combate, aventuras que o apazigúem ou o excitem. Em outros devaneios, a água imaginária nos aparecerá como o elemento das transações, como o esquema fundamental das misturas". 
poetas românticos alemães. É a água do lago, noturna, leitosa e lunar onde a libido desperta:

\begin{abstract}
A água, essa filha primeira, nascida da fusão aérea, não pode renegar sua origem voluptuosa e, na terra, ela se mostra com uma celeste onipotência como o elemento do amor e da união [...]. Não é em vão que os sábios antigos procuram nela a origem de todas as coisas [...]. E as nossas sensações, agradáveis ou não, não são mais, afinal, que as diversas maneiras de escoar em nós dessa água original que existe em nosso ser. O próprio sono não passa do fluxo desse mar invisível, universal, e o despertar é o começo do seu refluxo (NORVALIS, apud CHEVALIER; GHEERBRANT, 1998, p. 21).
\end{abstract}

Nas tradições judaica e cristã, a água simboliza, primeiramente, a origem da criação: fonte de todas as coisas ela é mãe e matriz; é útero. Mas, como é fonte de vida, é também fonte de morte. É criadora e é destruidora. Todo o Antigo Testamento celebra a magnificência da água. Na Bíblia os poços, as fontes, os rios são agentes de fertilização de origem divina, trazendo consigo a fecundidade e manifestando a benevolência divina. Os poços são lugares sagrados e perto deles nasce o amor e os casamentos principiam. É também símbolo de segredo, de dissimulação da verdade. As fontes são o símbolo da maternidade. Sua sacralização é universal, pois constituem a água virgem e, em muitas culturas são protegidas por tabus.

O simbolismo do rio é, ao mesmo tempo, o da fertilidade, da morte e da renovação. Entre os gregos os rios eram objeto de culto, quase divinizados, como filhos do Oceano e pais das Ninfas. Não se podia atravessá-los senão após cumpridos os ritos da purificação e da prece:

Não deveis atravessar jamais as águas dos rios de eterno curso, antes de ter pronunciado uma prece, com os olhos fixos em suas correntes magníficas, e antes de ter mergulhado vossas mãos nas águas agradáveis e límpidas. Aquele que atravessar um rio sem purificar as mãos do mal que as macula, atrairá sobre si a cólera dos deuses, que lhe enviarão, depois, castigos terríveis (HESÍODO, apud CHEVALIER; GHEERBRANT, 1998, p. 781).

Patri (Apud CHEVALIER; GHEERBRANT, 1998, p. 781), em sua Nota 
sobre a simbólica heraclitiana da água e do fogo, observa que:

[...] a palavra rios, no plural, não significa a pluralidade dos braços de um rio; existe um rio para cada homem que mergulhar em suas águas. No sentido simbólico do termo, penetrar (ou mergulhar) num rio significa, para a alma, entrar num corpo. O rio tomou o significado do corpo. A alma seca é aspirada pelo fogo; a alma úmida é sepultada no corpo. O corpo tem uma existência precária; escoa-se como a água, e cada alma possui seu corpo particular, a parte efêmera de sua existência - seu rio próprio.

Enfim, tantas janelas do imaginário das águas abrem-se neste texto, sugerindo desatar a imaginação criadora, num convite à entrega ao devaneio e à reflexão. Uma das janelas abre-se para os banhos.

\section{Os banhos: (des)prazer}

Do final da Idade Média até meados do século XVIII a limpeza dispensava a água e ignorava o corpo, excetuando-se o rosto e as mãos, únicas partes expostas. A água era rejeitada como um agente perigoso, que penetrava por toda parte. A água era capaz de se infiltrar no corpo e, especialmente a água quente, fragilizava os órgãos, abrindo os poros para os ares malsãos. O corpo banhado tornava-se permeável aos ares infectos que ameaçavam entranhar-se nele por todos os lados. A luta contra a peste, no final da Idade Média e na época clássica, fez com que as coletividades tivessem pavor do contato: era preciso restringir os intercâmbios. Dessa forma vários regulamentos internos foram elaborados e os "conselhos" referiam-se também à higiene individual e, necessariamente, aos banhos. Os médicos, em tempos de peste, denunciavam as casas de banho onde conviviam os corpos nus e indicavam que as pessoas fugissem das estufas e dos banhos. Um número cada vez maior de cidades impunha o fechamento das casas de banhos e estufas (VIGARELLO, 1996, p. 9)7.

7 Vigarello (1996, p. 9): "Essas decisões serão, de início, hesitantes. Des Pars, por ocasião da peste de 1450, reclama em vão dos escabinos de Paris a interdição das estufas, obtendo apenas a cólera dos donos desses estabelecimentos [...] O fechamento temporário e repetido, a cada epidemia, impor-se-á, no entanto, na lógica dos isolamentos. No século XVI esse fechamento torna-se oficial e sistemático". 
Imagens confusas da pele infiltrada pela pestilência, ares malsãos, males indefinidos fazem pensar também na possibilidade da gravidez na estufa decorrente de algum espermatozoide que permaneceria na tepidez da água (GRAFF apud VIGARELLO, 1996). Todas essas imagens tiveram sucesso suficiente e superaram os discursos médicos, sendo adotadas pelas mentalidades até se banalizarem. O banho foi cercado de regras imperativas sugerindo-se repouso, acamamento, proteção dos corpos com roupas. Com tanta recomendação, a prática do banho tornava-se complexa e rara.

As práticas privadas dos banhos também vão lentamente sendo eliminadas nos séculos XVI e XVII. As banheiras transformaram-se em tanques dos jardins e integraram-se a outro circuito da água - a água era apenas para olhar, para seduzir a visão; um espetáculo das naturezas disciplinadas privilegiando-se as teatralizações dos jogos aquáticos (TEYSSÈDRE apud VIGARELLO, 1996). A toalete então, na maioria das vezes, era 'seca', consistindo no friccionar-se e perfumar-se. Várias disposições constavam das civilidades do século XVII para que se esfregasse e não se lavasse. As crianças deveriam limpar as faces e os olhos utilizando tecido branco. A lavagem com água prejudicaria a vista além de provocar dores de dentes, catarros e empalidecer o rosto. Os higienistas do século XVII, dentre eles Jean du Chesne, descreviam e prescreviam a maneira de se fazer a toalete. A rejeição à água não eliminava a prática da limpeza. $\mathrm{O}$ seu uso restringia-se apenas à lavagem das mãos e da boca. Nos tratados de civilidade os temas se aprofundam com o tempo. No manual de Jean-Baptiste de La Salle, datado de 1736, as normas são mais rigorosas do que as de Erasmo, datadas de 1530, indicando como desengordurar os cabelos com pó e farelo sem utilizar a ablução. Dentre essas atitudes em relação aos corpos, a água quente e depois a fria eram indícios de novas distinções sociais:

Porém ao mesmo tempo insere-se numa nova imagem do corpo que ultrapassa o savoir-vivre: a higiene reabilita a intimidade corporal e legitima a procura de uma melhor utilização dos recursos orgânicos. Enfocada pela medicina e depois levada às escolas, logo se tornará, aliás, o dispositivo inédito de uma nova forma de controle coletivo dos comportamentos (REVEL, 1991, p. 191).

A história do asseio não é isolada e implica uma nova sensibilidade que, em meados do século XVIII, permitiu novas ideias sobre a água e a higiene. Reconhece-se no mundo dos gestos reprovados a silenciosa evolução de outra forma de intimidade. Enfim, o texto de La Salle que, inicialmente foi destinado 
aos alunos das Escolas Cristãs, foi alvo de imensa difusão nos séculos XVIII e XIX e levou ao extremo o controle corporal exigido tanto pela moral cristã quanto pela polidez. O modelo cortesão se opunha à civilidade erasmiana e a seu sonho de transparência social. A arte social - a civilidade - fez o século XVII esquecer a existência de um corpo próprio para impor uma autorrepresentação que satisfizesse as normas do grupo. Ao mesmo tempo em que se impunha por toda a parte a aparência, a crença no gesto justo e a fé na existência de uma semiologia geral dos comportamentos, unívoca e válida para todos, como fundamento do trato social, foram questionadas e denunciadas por serem construídas. Problematiza-se a civilidade: mentira, engano, vaidade ou simplesmente ridículo? A verdadeira civilidade traduziria as disposições caridosas da alma cristã e, a falsa, seria repleta de afetação e calculismo e objetivaria enganar as pessoas.

Rousseau, no século seguinte, apela ao coração e à razão contra a tirania dos costumes, requerendo no Émile as virtudes reencontradas de uma natureza moral e boa. Ele será educado à margem da sociedade a fim de estar mais bem preparado para a mesma. Com Rousseau foi estabelecido um novo modo de enfocar a infância e a educação: no seio das relações naturais e privadas. Nos anos da Revolução Francesa, civilidades republicanas tentaram o impossível casamento da educação proposta por Rousseau com as fórmulas de Erasmo, revistas e corrigidas. O conflito entre o que relaxa e o que comprime; entre o que amolece e o que endurece fez com que o banho frio, no século XVIII, fosse alvo de estudos dos terapeutas para utilização em tratamentos atribuindo-se a ele vantagens consideráveis: o frio no corpo comprime as partes exteriores e as vibrações das fibras tornam-se mais tensas, o sangue e os espíritos circulam com maior velocidade. A água fria serve também para atenuar o sangue, torná-lo mais fluido, despertar os espíritos animais e fazê-los circular mais rapidamente; facilitam a digestão, abrem o apetite e tornam o corpo mais ágil e vigoroso (JACQUIN apud VIGARELLO, 1996).

Além do funcionamento orgânico, da mecânica das fibras no contato com a água fria, outra pretensão existia: o ascetismo na prática do banho frio. $\mathrm{O}$ endurecimento seria tanto moral quanto físico:

Enquanto os romanos, ao sair do Campo de Marte, iam lançar-se no Tibre, foram os donos do mundo. Porém os banhos quentes de Agripa e de Nero pouco a pouco fizeram deles escravos [...] Os padres conscritos, portanto, bem tiveram razão em se opor às termas, mas a tropa dourada, infetada pelo luxo asiático, triunfou sobre a resistência e a virtude dos padres conscritos [...] Roma não se perdeu através de uma juventude que desdenhava se banhar na água fria, abandonada à moleza, tornando-se quase semelhante a nossos janotas, por ter deixado de lado os exercícios 
físicos que constituíam sua força e sua virtude? (TRONCHIN apud VIGARELLO, 1996, p. 132-133).

Muitos exemplos de práticas em água fria foram evidenciados por esse médico enciclopedista e seus amigos, citando os habitantes do istmo da América, os índios da América, os de La Hontan e os de Le Beau. Todos esses exemplos idealizavam o vigor e visavam promover a Antiguidade como modelo de lutas, jogos, exercícios, corridas, movimento. Seu sentido era social e opunha-se ao banho quente, tomado nos palacetes pela burguesia e que amolecia. A austeridade do frio era considerada superior aos prazeres julgados fáceis demais. As práticas quentes inclinavam às fraquezas e as práticas frias ao vigor. A isso se somava a crítica ao artificial, os corpetes, as roupas sufocantes, os besuntados nos cabelos, dentre outros.

Um primeiro estabelecimento para frequência pública foi construído sobre o Sena em 1761. Era um projeto terapêutico e higiênico destinado aos ricos. O estabelecimento foi o precursor dos banhos do século XIX. Certas práticas transformaram-se, como por exemplo, o banho de rio, que era reservado aos jogos ou a tratamentos isolados e indicado como saudável, como exercício reforçador, como técnica revigorante.

\section{A esfera do íntimo}

As sociedades europeias do século XVI ao XVIII sufocaram o indivíduo sob o peso dos comportamentos familiares, comunitários, cívicos e rurais. $\mathrm{O}$ quê pertencia à esfera do íntimo? Que lugares pertenciam a alguém único no tempo e no espaço? - o jardim fechado, o quarto, a ruelle - que se constituía do espaço entre a parede e o leito -, o gabinete ou o oratório e as lembrançasobjeto: o livro, a flor, a roupa, o anel, a fita, o retrato, a carta. O quarto também era um espaço íntimo. Os pintores dedicavam-se a representar as atividades que só se realizavam no quarto. Watteau, Boucher e Greuze pintavam temas íntimos e eróticos já representados pelos pintores holandeses do século anterior tornando-os mais explícitos:

Watteau vai além das convenções em A Toalete Íntima. Uma jovem de camisola aberta está sentada na cama preparando-se para o banho. 
Uma criada segura uma bacia e passa-lhe uma esponja. O tema é banal, porém o quadro é tão explícito que o observador - mesmo no século XX - sente-se um intruso. Com efeito, toda a educação contemporânea nos leva a desviar o olhar desses atos privados. As dimensões do quadro são bastante reduzidas; para vê-lo bem é preciso aproximar-se, transformar-se imediatamente em voyeur. A mulher banhada nada faz de indecente, mas o espectador que contempla o quadro é levado à indecência. As estatuetas e quadros de belas mulheres nuas brincando com um cão que se esconde entre suas pernas obrigam a deixar de lado a civilidade: quem vê essas obras sempre resvala no impudor do privado (RANUM, 1991, p. 226).

$\mathrm{O}$ voyeurismo decorria, já no século $\mathrm{XV}$, dos cuidados com o corpo feminino que tornaram-se lugar comum do erotismo. Esses cuidados passavam-se em público, no momento dos banhos públicos. Também as damas no banho nos próprios quartos foram pintadas rodeadas de criadas, de lareiras, de móveis. Os pintores da Escola de Fontainebleau representaram essas damas nuas parecendo felizes em seu autoerotismo; representavam-nas também posando como Vênus ou Diana, tendo por cenário um bosque com um curso d'água para o banho ou em um montículo de terra. As fontes e lavadouros eram locais privilegiados de contatos e censuras que se transformavam em rumores. Lugar frequentado por mulheres. A vizinhança era o tribunal da reputação. Não só a vizinhança intervinha na intimidade da família burguesa, mas também os criados realizavam uma espionagem doméstica - viam e ouviam pelo buraco da fechadura - mas, eram negados como pessoa e tidos como assexuados:

A marquesa de Châtelet, no século XVIII, podia ser banhada com a maior indiferença por seu criado de quarto Longchamp, de cuja virilidade, porém, tinha consciência suficiente para fazê-lo sentir-se embaraçado, como confessa em suas Mémoires. Cento e cinquenta anos depois, a sala de banho, transformada em santuário, fecha-se sobre a nudez dos senhores que já não toleram ser vistos por seus criados (PERROT, 1991, p. 182).

A mão que servia não era considerada a de uma pessoa. $\mathrm{O}$ criado, diligente e atento, dentre muitas outras tarefas, mantinha o calor da água, controlava a caldeira, derramava água diretamente na tina com o devido cuidado para não queimar a marquesa. Longchamp confessa seu constrangimento, a mão trêmula ao despejar a água do banho (LONGCHAMP ET MAGNIÈRE apud VIGARELLO, 1996). 
O banho integrava-se ao cotidiano e transformava, também, além das práticas da água, a das decências privadas. No final do século só banhistas mulheres serviram as grandes damas. E, muito lentamente, o banho, por volta dos meados do século XVIII, começa a mudar de status. Nessa época, a imersão na água continha efeitos que dominavam a imaginação; correspondiam a uma sucessão de ações cuja influência sobre o corpo estava longe de ser apenas limpeza. A água quente tida como a mais penetrante, a morna moderava os aquentamentos e a fria suscitava contrações que reforçavam os músculos e os vigores (VIGARELLO, 1996).

O novo interesse pelo banho fez com que inúmeras monografias médicas, em meados do século XVIII, discorressem sobre o assunto. AAcademia de Dijon, em 1755, propôs o seguinte tema: "As virtudes do banho aquoso simples". A teorização médica discutia a influência dos abalos produzidos no interior dos órgãos e os fenômenos de sensibilidade. Tratava-se, portanto, de descrever e reconstituir um estado de deleite que o banho quente provocava, atingindo os sentidos por sua própria substância que não é neutra, causando deleite, tornando o banho calmante, incitando o sono. Le Médecin des Dames em 1772, prescreve os banhos como uma prática sazonal indicando a primavera e o verão como as estações mais favoráveis. Mas essa é uma prática de luxo e os primeiros a se entregarem a essa "moleza" aristocrática em meados do século XVIII não serão os mesmos que um ou dois decênios depois descobrem as virtudes do banho frio coadunados com o ascetismo: lascívia opondo-se a uma prática austera.

Os gabinetes de banho eram raros, existindo apenas nas residências dos nobres, consistindo então em locais de refinamento e estética. Um exemplo disso é uma descrição apresentada no conto publicado por Bastide em 1753, La Petite Maison, em que o Marquês de Frémicour impressiona uma mulher mostrandothe a casa que construiu às margens do Sena, em Paris. O aposento dos banhos tem especial destaque com seus mármores, porcelanas e musselinas. $\mathrm{O}$ banho tinha um novo lugar. Esse conto, publicado no jornal Econômico, misturava os temas da técnica ao da sensibilidade, do luxo ao do progresso. Retomam-se as proposições de Voltaire: o refinamento das artes é condição para o refinamento dos sentidos (VIGARELLO, 1996).

Casanova, ao descrever o apartamento que o embaixador da França lhe emprestou em Veneza, em 1754, para facilitar seus encontros amorosos, via na banheira um local especial em que se misturava erotismo e sensualidade relegando a segundo plano qualquer razão funcional (VIGARELLO, 1996). Em 1759 um texto sobre a arte da beleza introduzia um longo elogio ao banho pleno de elementos do imaginário sobre o harém oriental: 
Com o banho da odalisca, o prazer sempre prevalece um pouco sobre o útil, e o efeito sobre os sentidos prevalece sobre o asseio. O cenário do serralho, descrito pelo autor, designa a volúpia: o nácar, as pérolas, as plantas aromáticas, a própria banheira transformada em concha, criam mais do que um efeito de ambiente. Tais objetos designam antes de tudo o meio. Cada gesto não é totalmente aplicável à lavagem. Sustentado por um imaginário das delicadezas e das preciosidades, o banho não poderia ser simples prática funcional. Esplendor das culturas refinadas, ele trabalha a sensação. Uma vez banhada, a odalisca pode "entregar-se aos braços de um sonho suave e voluptuoso. Ela é ao mesmo tempo sereia e languidez (CAMUS apud VIGARELLO, 1996, p. 114).

As pessoas insurgiam-se cada vez mais contra as disciplinas das coletividades e as servidões familiares, expondo sua necessidade de um tempo e de um espaço para si mesmas. Correntes anarquistas individualistas fizeram-se presentes na virada do século contemplando a liberdade do corpo, gosto pela natureza, pelo esporte, pelo amor livre. Tais audácias, porém, esbarravam nos comportamentos convencionais. Por exemplo, nas classes abastadas, o código de boas maneiras proibia uma moça de se admirar nua, mesmo através dos reflexos de sua banheira. Haviam "pós especiais" para turvar a água do banho, de forma a prevenir essa vergonha. Havia o temor de se despertar o desejo sexual suscitado pela água quente. O pudor estava diretamente relacionado ao desnudamento dos corpos e às apalpações que ele provoca. Havia a suspeita do olhar e dos gestos. Esfregar os órgãos genitais constituía um problema e a recomendação era para que se fechasse os olhos até terminar a higiene. As reservas eram evocadas utilizando-se uma linguagem que não nomeava os perigos. Alguns médicos exploravam o assunto considerando a banheira perigosa por sugerir "maus" pensamentos e o banho uma ofensa ao pudor constituindo-se um perigo para os costumes permanecer uma hora nua dentro de uma banheira (LÉONARD apud VIGARELLO, 1996).

O uso da banheira de metal, móvel, antecede a instalação dos sistemas modernos, fixos devido ao encanamento. Aos poucos, cria-se um novo espaço de intimidade onde, ao abrigo de qualquer intromissão que ameace seu pudor, a mulher pode pavonear-se, ler, sonhar. Os riscos do excesso de abandono dos corpos imersos na água estavam presentes também nos internatos. Os banhos quentes, nos colégios, só eram permitidos para doentes que não eram deixadas sozinhas (COURTEILLE apud VIGARELLO, 1996). As religiosas ofereciam camisas às pensionistas para que estas pudessem banhar-se. Com tantos perigos envolvendo a imersão na água, as famílias da elite, até finais do século XIX, resistiam à prática dos banhos: "Ninguém da minha família tomava banho! Nós 
nos lavávamos numa tina com 5 centímetros de água, ou nos esfregávamos com esponja em grandes bacias, mas a idéia de mergulhar na água até o pescoço parecia pagã, quase culposa" (PANGE apud VIGARELLO, 1996, p. 194).

O mesmo autor relata que, em 1900, a menina Pauline de Broglie teve febre alta e o médico prescreveu um banho. A casa era riquíssima, mas não tinha banheira, que foi alugada. Surgiu, então, uma nova questão: a menina deveria ficar nua nas águas do banho? Optou-se por banhá-la com a sua camisa de noite. Mesmo no banho o corpo permanecia oculto e a mulher evitava olhar para o tornozelo nu. Outras prescrições antigas diziam respeito à lavagem da cabeça. Os pentes e pós-secativos continuavam tendo a preferência.

\section{Considerações finais}

A água encanada chegou às casas parisienses em 1865. O banheiro tinha vasos e bacias e sua função não era de uso cotidiano. A água adquiriu valor depois das descobertas de Pasteur: a lavagem das mãos tornou-se uma obrigação social. Na primeira metade do século XIX havia, portanto, uma diversidade de banhos dos mais ricos: água morna facilitando as energizações orgânicas, água quente servindo para a distensão íntima e a água utilizada nas hidroterapias. Habitações modernas também eram oferecidas à classe operária contendo ar, luz e água: tomadas de água em cada andar; lavanderia em uma construção especial, provida de secadoras; casas de banho e piscina coberta.

Em torno de 1900, difunde-se, então, o sanitário e o banheiro. A porta tinha um ferrolho e o corpo nu experimentava sua mobilidade longe de qualquer intromissão. A difusão da prática do banho, entretanto, implicava também no convencimento das pessoas de que ela não ofendia o pudor, pois enxergava-se na água um vício incipiente em que se associavam a tepidez à lascívia.

Enfim, não tem fim! Afinal, são muitas janelas sobre imaginário das águas e suas relações com um corpo sexuado. 


\section{REFERÊNCIAS}

BACHELARD, Gaston. Os Pensadores. Vida e Obra. A Filosofia do Não. O Novo Espírito Científico. A Poética do Espaço. Seleção de textos de: José Américo Motta Pessanha. Tradução de: J. J. M. Ramos. São Paulo: Abril Cultural, 1978.

. O Direito de Sonhar. Tradução de: José Américo Pessanha et al. São Paulo: DIFEL, 1985.

. A Formação do Espírito Científico: contribuição para uma psicanálise do conhecimento. Tradução de: Estela dos Santos Abreu. Rio de Janeiro: Contraponto, 1996.

. A Água e os Sonhos: ensaio sobre a imaginação da matéria. Tradução de: Antonio de Pádua Danesi. São Paulo: Martins Fontes, 1998.

. A Psicanálise do Fogo. 2. ed. Tradução de: Paulo Neves. São Paulo: Martins Fontes, 1999.

CHEVALIER, Jean; GHEERBRANT, Alain. Dicionário de Símbolos.12. ed. Tradução de: V. da C. e Silva. Rio de Janeiro: José Olympio, 1998.

DURAN, Gilbert. As Estruturas Antropológicas do Imaginário. [S.l.: s.n.], 1997.

ELIADE, Mircea. Imagens e Símbolos. Ensaio sobre o Simbolismo Mágico-religioso. Prefácio de: Georges Dumézil. Tradução de: Sonia Cristina Tamer. São Paulo: Martins Fontes, 1996.

PERROT, Michele. Figuras e Papéis. In: . História da Vida Privada. Vol. VI: Da Revolução Francesa à Primeira Guerra. São Paulo: Companhia das Letras, 1991.

PESSANHA, José Americo Motta. Bachelard e Monet: o olho e a mão. In: NOVAES, Adauto (Org.). O Olhar. São Paulo: Companhia das Letras, 1988.

RANUM, Orest. Os Refúgios da Intimidade. In: CHARTIER, Roger (Org.). História da Vida Privada. Vol. III: Da Renascença ao Século das Luzes. Tradução de: FEIST, Hildegard. São Paulo: Companhia das Letras, 1991.

REVEL, Jacques. Os Usos da Civilidade. In: CHARTIER, Roger (Org.). História da Vida Privada. Vol. III: Da Renascença ao Século das Luzes. Tradução de: FEIST, Hildegard. São Paulo: Companhia das Letras, 1991.

VIGARELLO, Georges. O Limpo e o Sujo: uma história da higiene corporal. Tradução de: Mônica Stahel. São Paulo: Martins Fontes, 1996.

Texto recebido em 3 de junho de 2009.

Texto aprovado em 10 de julho de 2009. 